\title{
Challenges to Coordination: Understanding Intergovernmental Friction During Disasters
}

\author{
Daniel P. Aldrich ${ }^{1}$
}

Published online: 2 September 2019

(C) The Author(s) 2019

\begin{abstract}
While idealized crisis response involves smooth coordination between relevant actors, friction between levels of government and between the state and civil society in responding to catastrophe may be more common. This article builds a theory of cross-level friction during and after crisis by analyzing the conditions when discord is most likely. With a medium- $N$ dataset $(N=18)$ of disaster responses from, among other countries, Chile, Haiti, Japan, North America, the Philippines, and Somalia, I carry out quantitative and qualitative analysis of cases with a variety of levels of friction to investigate the conditions that lead to misalignment. Tobit regression, qualitative comparative analysis, and case studies that take into account levels of economic development, government structure, nongovernmental organization density, and levels of damage demonstrate that low levels of development, lower levels of economic costs from the crisis, and poor planning and logistical infrastructure correlate with a higher likelihood of friction between disaster response stakeholders. Although not definitive, these findings come with theoretical and practical implications as climate change makes extreme weather events and future disasters more likely and more powerful.
\end{abstract}

Keywords Bottom up culture - Case studies · Disaster coordination - Qualitative comparative analysis - Tobit regression analysis . Top down institutions

Daniel P. Aldrich

daniel.aldrich@gmail.com

1 Department of Political Science, School of Public Policy and Urban Affairs, Northeastern University, Boston, MA 02115, USA

\section{Introduction}

All societies hope to minimize the casualties, property damage, and business interruption that come with disasters that, because of human induced-climate change, are becoming more costly (Below and Wallemacq 2018). A number of policies reduce the human and economic costs of crises, including preventing settlement in vulnerable areas through zoning laws, wide scale evacuation before the event, and rapid and organized response from local and national authorities (Metaxa-Kakavouli et al. 2018). Successful post-disaster outcomes are not as common as observers would like. Experts have pointed to a handful of well-coordinated responses following disasters, including the intensive search after the Columbia shuttle disaster that resulted in locals and professional responders rapidly locating the bodies of the astronauts and critical debris from the shuttle. Similarly the largest boat evacuation in history after the 9/11 terror attacks on the Twin Trade Towers in New York City resulted in the successful evacuation of 500,000 people in an afternoon thanks to coordination between the Coast Guard and private boats (Boin and Bynander 2014). Successful disaster responses facilitate strong and rapid population return, generate access to capital for affected businesses and entrepreneurs, create stocks of permanent housing for the displaced, and rebuild the social safety net of schools, hospitals, and social services (BCLC 2010).

But failures in coordination and communication during disaster response have become so common that they are expected (Boin and Richardson 2015). Some USD 95 million of international aid intended for victims of the 1984-1985 famine in Ethiopia was diverted to local warlords and corrupt aid officials, resulting in the deaths of many from preventable starvation. Satellite images from 
post-Hurricane Katrina New Orleans revealed a fleet of unused school buses that could have evacuated hundreds of residents from oncoming floodwaters had local and regional authorities shared information. In Japan, the Tokyo Electric Power Company did not train with local firefighters on equipment that could cool reactors during a meltdown. As a result of that choice and a lack of preparation at the local and national levels, three reactors at Fukushima Dai-ichi melted down within $50 \mathrm{~h}$ of Japan's $3 / 11$ earthquake and tsunami (Naderpajouh et al. 2018). In all of these cases observers agreed that better coordination-the alignment of goals and methods across multiple levels of response activity-would have created better outcomes, measured in lower mortality rates, more rapid medical service and food delivery, and less waste. I build on past research that has labeled the failure to coordinate effectively as "friction" (Siembieda 2012).

Despite the pressing urgency of disaster response, the conditions under which local, regional, and national authorities and residents synchronize well during disaster remain vague. As a result, proposals to ameliorate discord and a lack of coordination have often focused on technical fixes, such as building shared datasets on disasters (Eyra et al. 2001) and new, phone-based technologies that can gather data from multiple sources (Oden et al. 2012). Moving away from individualized or technical fixes based on uncertainty, this article systematically evaluates the conditions when friction is more likely using a new dataset of 18 disasters from countries with a mix of development levels, governance systems, and friction. Data about each crisis include information on the level of development, governance, the cost of the disaster as a percentage of overall gross domestic product (GDP), the percentage of population killed, nongovernmental organizations (NGOs) per capita, and level of goal sharing. Recognizing warnings from scholars that attempts to judge overall "success" of a disaster response in binary terms "does not adequately describe the problem" (Boin and Richardson 2015), I instead code disaster response "coordination."

After an initial Tobit regression analysis, I move to a qualitative comparative case (QCA) approach (Ragin 2000) and three mini-case studies to understand when friction is most (or least) likely. Across all three types of analysis (regression, QCA, and case studies), I find that low levels of development, lower economic costs from the crisis, and poor planning and logistical infrastructure correlate with friction. Such mismatches and chaos reduce the efficiency of what ideally would be a joint bottom-up and top-down response process. "This lack of coordination in providing humanitarian assistance can be an enormous hurdle [...that] will hinder a proper response to the needs of the affected population" (WHO 2013, p. 1).
This article contributes to the growing literature on disasters and resilience in several ways. First, rather than merely describing cases of cooperation or discord, this article uses mixed methods to qualitatively and quantitatively evaluate the importance of various factors in coordinating disaster response. Where past investigations of friction during crisis have often relied on a single methodological approach — most commonly case studiesthis attempt moves between regression, QCA, and case studies. Rather than avoiding research topics that require a resource- and time-intensive data collection process, this research points to the potential for medium $N$ investigations for future research.

Next, where previous studies of disaster response have often relied on the analysis of a single case or handful of cases, this study uses data from 18 catastrophes around the world to avoid making inference based on a narrow range of cases from a single country or disaster (Johnson and Olshansky 2017). Instead of basing its results on developed or developing nations, or democratic or authoritarian ones, these findings may have more generalizability. Finally, the counterintuitive findings from this analysis help open up alternative policy responses in future disasters. For example, these data indicate that crises with lower economic costs may not create the sense of urgency that could help coordination between levels of government and civil society. By recognizing that "minor" disasters may in fact be ones where friction is more likely, civil and state authorities can better realize the need to find balance in their interactions.

The article is structured as follows: I first lay out the literature on coordination during crisis and then move to a discussion of potential factors that may minimize (or increase) the likelihood of friction. The middle of the article brings quantitative regression analysis, QCA, and mini-case studies to illustrate patterns of these factors and their relationship to coordination or friction outcomes in these datasets. I conclude the article with a discussion of the shortcomings of this study, future research agendas in this field, and policy recommendations.

\section{Literature on Intergovernmental Coordination During Crisis}

Countries around the world struggle to match bottom-up and top-down policies across a variety of public policy areas. Especially for countries with federal or quasi-federal governance systems that face a patchwork of conditions across their jurisdictions, bureaucrats and decision makers often strive to create a top-down, uniform framework for localities that matches bottom-up interests and capacities to facilitate governance in all policy arenas (Girdwood 2013). 
This is true even in policy fields that do not involve potential loss of life, extensive scrutiny from media, and high levels of regulatory oversight (if occasionally only ex post) as we find in disasters. For example, "[t]he challenge for the Netherlands-as well as for other countries-is to harmonize a national adaptation policy with its spatial planning policy" (De Bruin et al. 2009, p. 25). Government experts and decision makers typically hold access to cutting edge technology and literature on best practices. Nevertheless, local experts, because of their detailed knowledge of hyperlocal conditions, have a better grasp on how best to implement new plans.

So too in the field of energy efficiency, German cities experimenting with energy efficiency, renewable energy, and a smaller carbon footprint have not been able to find a sweet spot in their interactions with the central government. These localities need to balance a bottom-up, entrepreneurial culture of individual designers and architects with standardized top-down planning from regional and federal government experts who set laws and require national compliance (Fastenrath and Braun 2017). The Chinese central government must regularly renegotiate national environmental enforcement protocols and laws with thousands of regional and local governments with varying degrees of economic development and environmental pollutants (Shi et al. 2013).

With these regular problems of friction even in nonemergency policy areas, the challenges of coordination and communication during crisis have more severe and obvious consequences: lives are lost and recovery retarded should responders and decision makers fail to move resources, personnel, and aid in time to disaster struck communities. Nations have moved to create frameworks intended to better handle catastrophe coordination, as " $[\mathrm{t}]$ urning policy into practice requires finding the appropriate balance between top down and bottom up engagement" (GNDR 2009 , p. vi). Analysts have argued that the ideal disaster response involves simultaneous engagement from community- and locality-based resources in coordination with national authority plans and resources (Muir-Wood 2016). Precisely what that balance is, or the conditions under which it is likely to be reached, are not clear. North American authorities, for example, seeking to coordinate the actions of thousands of agencies, institutions, and NGOs around the country, built the National Disaster Recovery Framework (NDRF) in hopes of a harmonious response structure (DHS 2016). The NDRF mentions coordination more than 100 times in 53 pages. But few would argue that the United States has mastered the art of coordinated disaster response.

Scholars studying disaster response have sought to shed light on this problem in a variety of ways. One researcher created a framework for analyzing disaster coordination based on an economic model of the labor market that involves job seekers and employee seekers. Under such assumptions, governments and relevant actors-labeled external and internal agents in this framework-need information and engage in transactions for stabilization and recovery. In this model, communities hit by disasters serve as the internal agents while national government agencies like the Federal Emergency Management Agency (FEMA) are external ones who provide resources (Siembieda 2012). Other teams of researchers have argued that coordination in disaster response works best in conditions of "emergent coordination," that is, through indirect, unplanned, and spontaneous collaboration (Faraj and Xiao 2006, p. 1166). Other research has focused on the ways that government agencies and decision makers take credit (or blame) for the response pattern (Boin et al. 2008). Another investigation of extreme weather events and adaptation in the premodern world by Peregrine (2018) looked at greater local participation in decision making and coordination in a balance with the enforcement of norms, and described the core balance as one involving flexibility to adapt to changing circumstances and tight adherence to social norms.

Given this past research, a number of potential factors stand out for further systematic investigation: level of development, governance, impact of the disaster, civil society capacity, goal sharing between levels of governance, administrative capacity of regional and local governments, and level of logistics and planning. I investigate each of these factors and how they may correlate with disaster response coordination in turn below.

The level of development of a society or nation hit by disaster could impact the likelihood of friction in a number of ways (Manandhar and McEntire 2014). Developed societies, with higher levels of professionalization in their bureaucrats and higher levels of education, may have an easier time coordinating local and national responses. Alternatively developing societies, which more regularly have authoritarian or at least less democratic governance, may find that central authorities can steamroll or overcome local resistance to central plans.

The level of governance in a nation could be correlated with development and therefore have an impact on coordination ability afterwards a shock or disaster (Gall et al. 2014). More democratic and transparent societies might find collaboration easier as they would seek to consult with, rather than overrule, local disaster managers, town mayors, and regional governors. Democratic countries may envision civil society as a desired and active participant in the disaster response stage, helping to organize volunteers into organizations such as voluntary organizations active in disasters (VOADs), community organizations active in disasters (COADs), and other trained community-based aid givers. 
The cost of the disaster could potentially reduce or increase the transactions costs associated with coordination (Benson and Clay 2003). I envision costs in two ways: the economic costs of the crisis, captured here in terms of the disaster's costs as a percentage of overall GDP, and also the human cost, measured as a percentage of the population killed. When a society faces a larger disaster-with either higher human or economic costs-it may be more incumbent on the national government to show leadership by leading local governments and ignoring dissent. This was the case in China's 2008 Wenchuan Earthquake, the Chilean 2010 earthquake and tsunami, and Japan's 3/11 triple disasters. However, it may also be possible that, in a massive disaster that creates chaos and reduces the effectiveness of standard service providers in the area, the central government should back away from seeking to standardize and coordinate responses and allow local residents and governments to lead (Blakeman 2017). Or, as others have argued, "because recovery is a process rather than an outcome, it is best accomplished at local levels of government" (Johnson and Olshansky 2017, p. 9).

The ability of the civil society to coordinate and respond, measured here in terms of NGOs per capita, can also alter whether outcomes move smoothly (Shaw and Godao 2004). As with previous variables, the impact of higher levels of NGOs per capita is unclear. It may be that having more NGOs provides little space for top-down decision making and opens the way for conflict and disconnection post crisis. Alternatively societies with more NGOs may be more democratic and therefore more likely to see NGOs as an ally of local, regional, and national governments during crisis.

How well the local authorities and the central government harmonize their visions of a response - a variable I label "goal sharing" - may alter the trajectory of the response (Edgington 2010). If the national government uses the disaster response as a chance to clear residents from vulnerable areas, for example, that may disconnect with local plans of increasing livable and affordable housing in the area. If the central government regularly coordinated before a disaster shock with local authorities on extreme weather, resilience, and disaster management plans-as has been the case in the Netherlands, for example - the arrival of a different major catastrophe, such as a flood, may provide another scenario where cooperation is likely.

Whereas NGO capacity captures the ability of the third sector to respond to needs, local capacity instead seeks to capture how well the local government is equipped to respond in a crisis. Some local governments find themselves underfunded through local tax revenue and heavily dependent on the central government for administrative and financial resources - as in Japan. In other cases local cities and regions may themselves have tremendous resources - such as New York City - and be able to coordinate their own well-oiled responses to crises.

The ability of the society to get personnel, material, and information where it needs to go during a crisis can be categorized in terms of the strength of logistical infrastructure. Even before the Haiti Earthquake, for example, that nation struggled to provide potable drinking water, education, and health care to its citizens. After the earthquake killed many members of the armed forces, police and fire teams, and government officials, it became even more of a struggle for the government to assist its citizenry. In contrast Japan's air, rail, road, and shipping infrastructure made it possible to deliver needed relief supplies within days even to the most damaged areas of Tōhoku following its $3 / 11$ triple disasters.

The degree to which all authorities engaged in realistic disaster planning may serve as a final factor that can influence coordination or discord after disaster. While colleagues have referred to such plans as "fantasy documents" (Clarke 1999) because of their tremendous disconnect from reality, some communities have invested time and effort in building pragmatic frameworks for response and recovery.

\section{Data}

Using a variety of public sources, including EM-DAT (CRED 2019), secondary and tertiary sources from newspapers, and academic articles, I assembled a dataset on 18 disasters ${ }^{1}$ that took place over the past five decades across developing and developed countries alike. I selected these 18 disasters for several reasons. First, they represent a strong cross section of nations at various levels of

\footnotetext{
${ }^{1}$ A full list of the disasters in chronological order:

Bhola Cyclone, East Pakistan 1970

Kobe Earthquake, Japan 1995

9/11 Manhattan Port Evacuation, USA 2001

Columbia Explosion, USA 2003

Chuetsu Earthquake, Japan 2004

Indian Ocean Tsunami, India 2004

Hurricane Katrina, USA 2005

Pakistan Earthquake 2005

Cyclone Nargis, Myanmar 2008

Chile Tsunami 2010

Haiti Earthquake 2010

Monsoon Floods Pakistan 2010

Thai Floods 2011

Japan's Triple Disaster 2011

Somalia Droughts 2011

Iran Earthquake 2012

Typhoon Haiyan, Philippines 2013

Hurricane Irma, USA 2017.
} 
development, from developing, to mid-range developed, to advanced development. Next, these disasters bring with them a wide range of government capacity and democracy. These disasters draw from a number of regions around the world, including Africa, the Americas, and Asia. Finally, these disasters have a broad range of economic and human costs, from very few deaths to $0.05 \%$ of the overall nation's population. Most of the cases come after 2001 because of the availability of consistent data on these events. Using a team of coders I sought to capture the variables outlined above from secondary and tertiary reports in relatively simple terms, often using a binary outcome but at other times using a continuous scale if it was feasible across all observations. The unit of analysis is therefore the disaster response itself. Table 1 lays out the variables, their means, standard deviation, minimum, and maximum.

\section{Methodology}

Moving beyond a descriptive approach, I use quantitative regression analysis, qualitative comparative analysis, and case studies (in that order) to illustrate how factors may influence coordination or friction in crisis.

\subsection{Tobit Regression Analysis}

To better shed light on which of these factors result in friction as opposed to coordination I begin with the Tobit censored regression model (as the dependent variable here measuring friction or coordination has a maximum value of 1). With fewer than 20 observations, its results are more suggestive than definitive. Table 2 provides the estimated Tobit regression coefficients.

Using this pilot quantitative analysis of the dataset, and holding other factors constant, three factors stand out as statistically significant, defined here as those Tobit coefficients with $p$ values of equal to or less than 0.05: the level of development, the economic cost of disaster, and logistical infrastructure. Level of development, disaster cost, and logistical capacity come with a negative coefficient indicating that as these factors rise, friction is less likely. These estimates would indicate that low levels of development, low economic costs, and poor logistics make friction more likely. These preliminary findings based on a quantitative analysis of a small dataset require further investigation and I use QCA to do so.

\subsection{Qualitative Comparative Analysis}

The underlying principles of qualitative comparative analysis (QCA) rest on the belief that measurable outcomes in empirical processes come from multiple paths (Thomas et al. 2014). That is, friction during a crisis may not solely be a function of governance, but rather governance, high economic costs, and poor logistics interacting with each other. By themselves, any one factor may be necessary but insufficient to trigger friction. As quantitative regression models are hard pressed to test various combinations of factors (and instead test each in isolation of the others), QCA builds on Boolean logic and truth tables to probe combinations and recipes involving various levels of factors (Ragin 2000). Qualitative comparative analysis bridges qualitative and quantitative methodologies, allowing for process tracing through verifiable and testable evaluation. For this study, rather than using purely binary outcomes (often labeled crisp sets) as with earlier research involving truth tables, I use fuzzy set logic to allow partial membership in a category. Hence values can fall within the range of 0 to 1 rather than exclusively at 1 or 0 (in or out of a category) (Table 3).

Table 1 Descriptive statistics for 18 disaster events in the Americas, Asia, and East Africa

\begin{tabular}{|c|c|c|c|c|c|}
\hline Variable & $N$ & Mean & SD & Min & Max \\
\hline Level of friction & 18 & 0.639 & 0.345 & 0 & 1 \\
\hline Level of development & 18 & 0.444 & 0.511 & 0 & 1 \\
\hline Governance & 18 & 0.722 & 0.461 & 0 & 1 \\
\hline Disaster cost (percentage of overall GDP) & 18 & 0.049 & 0.073 & 0.001 & 0.259 \\
\hline Percentage of population killed & 18 & 0.005 & 0.013 & 0 & 0.046 \\
\hline NGOs per capita & 17 & 0.000 & 0.000 & $1.50 \mathrm{E}-06$ & 0.000215 \\
\hline Goal sharing & 18 & 0.500 & 0.514 & 0 & 1 \\
\hline Local capacity & 18 & 0.611 & 0.502 & 0 & 1 \\
\hline Strong logistics & 18 & 0.278 & 0.461 & 0 & 1 \\
\hline Planning & 18 & 0.500 & 0.514 & 0 & 1 \\
\hline
\end{tabular}


Table 2 Estimated Tobit regression coefficients for nine variables that explore the friction/coordination dichotomy in 17 disaster events

\begin{tabular}{|c|c|c|c|}
\hline Variable & Coefficient & Std. Error & $P$ value \\
\hline Level of development & -0.462 & 0.202 & 0.052 \\
\hline Governance & 0.500 & 0.323 & 0.161 \\
\hline Disaster cost (percentage of overall GDP) & -5.262 & 1.906 & 0.025 \\
\hline Percentage of population killed & 465.961 & 729.418 & 0.541 \\
\hline NGOs per capita & 7026.588 & 5003.716 & 0.198 \\
\hline Goal sharing & 0.159 & 0.238 & 0.524 \\
\hline Local capacity & -0.191 & 0.223 & 0.416 \\
\hline Strong logistics & -0.574 & 0.214 & 0.028 \\
\hline Planning & 0.109 & 0.196 & 0.595 \\
\hline Constant & 0.533 & 0.350 & \\
\hline /sigma & 0.203 & 0.046 & \\
\hline
\end{tabular}

$N=17$. Upper bound of Tobit set to 1

Table 3 Truth table for the disaster responses to nine interacting variables in 18 disaster events in the Americas, Asia, and East Africa

\begin{tabular}{|c|c|c|c|c|c|c|c|c|c|c|}
\hline Disaster & Dev & Gov & PercEconCost & PercKilled & NGOsperCap & Goal & Capacity & Logistics & Plan & $\begin{array}{l}\mathrm{Ou} \\
\text { tcome }\end{array}$ \\
\hline Bhola Cyclone, East Pakistan 1970 & 0 & 0 & 0.012 & 0.00517 & & 1 & 0 & 1 & 1 & 1 \\
\hline Kobe Earthquake 1995 & 1 & 1 & 0.018 & 0.00004 & 0.0000032 & 1 & 0 & 0 & 0 & 0.5 \\
\hline $\begin{array}{l}\text { 9/11 Manhattan Port Evacuation } \\
2001\end{array}$ & 1 & 1 & 0.005 & 0.00001 & 0.0000153 & 1 & 1 & 1 & 1 & 0 \\
\hline Columbia Explosion 2003 & 1 & 1 & 0.001 & 0.00000 & 0.0000024 & 1 & 1 & 1 & 1 & 0 \\
\hline Chuetsu Earthquake 2004 & 1 & 1 & 0.006 & 0.00000 & 0.0000032 & 1 & 0 & 1 & 1 & 0.5 \\
\hline Indian Ocean Tsunami 2004 & 0 & 1 & 0.001 & 0.00016 & 0.0000030 & 0 & 1 & 0 & 0 & 1 \\
\hline Hurricane Katrina 2005 & 1 & 1 & 0.008 & 0.00001 & 0.0000781 & 0 & 1 & 0 & 0 & 1 \\
\hline Pakistan Earthquake 2005 & 0 & 0 & 0.047 & 0.00048 & 0.0000279 & 0 & 1 & 0 & 1 & 0.5 \\
\hline Cyclone Nargis 2008 & 0 & 0 & 0.004 & 0.00005 & 0.0000015 & 1 & 0 & 0 & 1 & 1 \\
\hline Chile Tsunami 2010 & 0 & 1 & 0.137 & 0.00003 & 0.0000383 & 0 & 1 & 0 & 0 & 0.5 \\
\hline Haiti Earthquake 2010 & 0 & 1 & 0.259 & 0.03162 & 0.0000480 & 0 & 1 & 0 & 0 & 1 \\
\hline Monsoon Floods Pakistan 2010 & 0 & 1 & 0.054 & 0.00001 & 0.0000251 & 0 & 1 & 0 & 1 & 0.5 \\
\hline Thai Floods 2011 & 1 & 1 & 0.109 & 0.00001 & 0.0000144 & 1 & 1 & 0 & 1 & 0.25 \\
\hline Japan's Triple Disaster 2011 & 1 & 1 & 0.034 & 0.00014 & 0.0000032 & 0 & 1 & 0 & 1 & 0.5 \\
\hline Somalia Droughts 2011 & 0 & 0 & 0.170 & 0.04600 & 0.0002151 & 0 & 1 & 1 & 0 & 1 \\
\hline Iran Earthquake 2012 & 0 & 0 & 0.001 & 0.00000 & 0.0000564 & 0 & 0 & 0 & 0 & 0.75 \\
\hline Typhoon Haiyan 2013 & 0 & 1 & 0.008 & 0.00006 & 0.0000099 & 1 & 0 & 0 & 0 & 1 \\
\hline Hurricane Irma 2017 & 1 & 1 & 0.003 & 0.00000 & 0.0000029 & 1 & 0 & 0 & 0 & 0.5 \\
\hline
\end{tabular}

This study has sought to probe the role of nine factors (level of development, governance, and so on), and the number of possible combinations of these factors is quite large ( 2 to the 9 th power, or 512). These are far too many to test by hand or visual observation alone. Software can simplify and reduce the large number of potential combinations of cases so that in this case two combinations of characteristics stand out as significant as seen in Table 4, which provides details on the combination of factors that lead to friction along with their coverage and consistency levels.

The first pathway (which some scholars have called a "recipe") involves low levels of development, high governance, low economic costs, fewer NGOs per capita, low goal sharing, higher local capacity, poor logistics, and poor planning. This combination of factors has the best raw and 
Table 4 Qualitative comparative case (QCA) coverage of factors that produce friction in post disaster management in 18 disaster events in the Americas, Asia, and East Africa

\begin{tabular}{|c|c|c|c|}
\hline Set & Raw coverage & Unique coverage & Solution consistency \\
\hline $\begin{array}{l}\text { Set 1: devlevel*GOVTOPEN*perceconcost*ngospercap*goalshare } \\
\text { *LOCALCAPAC*logistics*plan }\end{array}$ & 0.213 & 0.21 & 0.861 \\
\hline $\begin{array}{l}\text { Set 2: devlevel*GOVTOPEN*PERCPOPKILLED*ngospercap } \\
\text { *goal-share*LOCALCAPAC*logistics*plan }\end{array}$ & 0.003 & 0 & 1 \\
\hline
\end{tabular}

Lower case indicates the lack of factor (hence devlevel means low levels of development) while upper case indicates high levels of the factor (therefore GOVTOPEN means an open and transparent democracy)

unique coverage, meaning these conditions are likely to lead to friction. The second potential combination is mostly similar to the first recipe except it has more people killed (as a percentage of population) rather than low economic costs. However, this second configuration of factors is far rarer among the 18 cases than the first set as seen in its raw coverage (0.003 as compared to 0.213$)$. Raw coverage explains the "extent to which each recipe can explain the outcome," while unique coverage is the proportion of cases that can be explained exclusively by that set (Legewie 2013 , p. 19). While the second combination of factors has higher solution consistency, its unique and raw coverages are very low in comparison, so the first set has more promise. The Tobit results from the previous section overlap strongly with these from QCA, namely both indicate that development, economic costs, and logistics seem to be critical factors in friction outcomes. Having seen strong overlap between these methodologies, I turn to cases on and off of the predicted outcomes to better ground these claims.

\subsection{Mini-Case Studies}

To briefly trace how these factors interacted in actual crises, I provide three mini-cases of the 2013 Typhoon Haiyan event in the Philippines, Japan's 3/11/2011 triple disasters, and the United States' 9/11/2001 Manhattan Port Evacuation response to the World Trade Center collapse disaster.

\subsubsection{Typhoon Haiyan Response}

Typhoon Haiyan (known regionally as Yolanda) made landfall in the Philippines on 8 November 2013 with $300 \mathrm{~km}$ per hour winds and four meter storm surges. Taking more than 6000 lives and affecting some 14 million people, the hurricane triggered a State of National Calamity and responses from domestic and international actors. It also revealed the consequences of social and economic inequalities in the nation that resulted in disparate outcomes for residents (Walch 2018). Despite the activation of evacuation and aid deliveries, this crisis response encountered a high level of friction ( 1 out of a maximum of 1 ) due to a lack of coordination between local, regional, and national agencies. To begin, "the Philippine government failed to anticipate the extent of the damage and miscalculated its own capacity to respond" (Yamada 2017, p. 77), likely because it lacked "an emergency plan that coordinated risk assessment, preparation, and resourcing" (Alcantra 2014, p. 342). With local governments overwhelmed by scale of the disaster (only 60 out of 2250 employees in Tacoban reported for duty, for example), the President himself took control of relief and response operations. But public feuding-what others have called the blame game (Boin et al. 2008) - between the central and regional governments further slowed the overall response and politicized it.

The central government overlooked the potential roles for regional and provincial level agencies along with international aid groups when it directed the response and recovery processes. This may be because nongovernmental agencies and civil society organizations lacked partnerships with Philippine government organizations at all levels (Dy and Stephens 2016, pp. iii-iv). During this major event the local and central governments ended up at odds with each other, openly politicizing the event and failing to respond harmoniously. In terms of the factors under study here, the Philippines has low levels of development, a relatively democratic governance system, a disaster with moderate levels of economic impact $(0.008 \%$ of the GDP), higher levels of its population killed $(0.00006 \%$ of overall population), modest numbers of NGOs per capita, low capacity, poor logistics, and poor planning. This disaster in the Philippines sits squarely on the predicted pattern created by the QCA truth tables. It also embodies the findings from the Tobit regression, namely that low levels of development, poor logistics, and moderate levels of economic damage are highly correlated with poor coordination in disaster response.

\subsubsection{Japan's 3/11 Triple Disasters Response}

On 11 March 2011 Japan experienced a massive triple disaster: a 9.0 magnitude earthquake followed by a series of tsunami (some as high as 20 meters, or 60 feet) and 
nuclear meltdowns at the Fukushima Dai-ichi nuclear power plants. With more than 18,400 people killed, 125,000 homes destroyed, and a cost of more than USD 235 billion in damages, these crises were accompanied by a moderate level of friction ( 0.5 out of 1$)$. Japan's central government undertook top-down response and recovery plans, sending in private engineering consultants to affected cities for over a year. Locals argued that Tokyo often ignored their wishes and that localities relied on cookie cutter plans in a rush to move forward (Dimmer 2017), a long recognized tension in the recovery process (Johnson and Olshansky 2017). Tokyo based bureaucrats pushed for $14.5 \mathrm{~m}$ seawalls against future tsunami despite little evidence that physical infrastructure had saved lives during the tsunami (Aldrich and Sawada 2015) and resistance from local communities hoping to maintain tourism and fishing industries through lower walls. Local governments in the affected Tohoku region had some plans in place to receive aid from localities further from ground zero through "sister city" agreements, such as Hyogo Prefecture bureaucrats assisting Sendai's local government, which had mixed results on the ground (Watarai 2012).

In responding to the ongoing nuclear disaster, the central government failed to provide guidance to mayors and governors on how to react to the radioactive contamination so that many communities faced additional danger by not evacuating to safe areas (Aldrich 2019). As a result of the poor coordination and information from the government, many residents in Japan became skeptical of the government's claims about the disasters and moved away from interactions with it to instead engage in citizen science, especially in the field of radiation exposure (Suzuki and Kaneko 2013). Japan's 2011 disasters involved high levels of development, a strong democratic governance system, high economic costs $(0.03 \%$ of the GDP), moderate levels of fatalities, high capacity, good planning, and poorly shared goals. This case sits slightly off the predictions of both the QCA and Tobit analyses as the models would predict that this disaster's characteristics would lead to lower levels of friction.

\subsubsection{The 9/11 2001 Manhattan Port Evacuation Response to the World Trade Center Collapse Disaster}

The final mini-case study draws on an event in North America. On 11 September 2001 coordinated terror attacks against the World Trade Center and the Pentagon took the lives of nearly 3000 people in Manhattan and Washington DC. With USD 10 billion in infrastructure damage, the crises remain the largest attack on American soil for the past two centuries. Despite the chaos of the day, the joint government and civil society response to evacuate civilians following the 9/11 terror attacks in Manhattan had a low level of friction (classified as a 0 out of 1). In the largest boatlift in history-even larger than the popularized account of the 1940 Dunkirk withdrawal of the UK and French troops during World War II-government and private sector vessels worked to evacuate all people south of the Twin Trade Towers within nine hours.

Following the attacks, half a million residents, office workers, and others sought to leave Manhattan but were stymied due to the shutdown of normal traffic out of many of the typically accessible tunnels and bridges from the island. Thanks to an "ad hoc flotilla of ferries, tugs, workboats, dinner cruise boats and other assorted harbor craft" some 500,000 people evacuated from Lower Manhattan by the end of the day in a case of "distributed sensemaking" (Kendra and Wachtendorf 2016, pp. 2, 30). The coordination was possible because of the low level of control exercised by the Coast Guard (which has jurisdiction over the area) and the emergent volunteers who came on a variety of private craft to assist when the Coast Guard called for all available boats. The 9/11 terror attacks response involved high development, strong democracy, low economic damage, low fatality rates, strong logistics, good capacity, and highly shared goals. It sits among the very few disaster responses that have achieved high ratings of coordination.

\section{Discussion}

One suggested solution to the friction found in many of the cases here and in the broader dataset involves advancing mitigation and response simultaneously in parallel at different levels. Local residents, experts urge, need to live in cultures of disaster while decision makers and national leaders must be part of strong institutions (Muir-Wood 2016). Local disaster culture translates into homeowners, families, and businesses being mindful of threats and risks and creating and drilling crisis responses. Institutional engagement means that decision makers and bureaucrats in national governments create and maintain strong regulations and governance practices that minimize harm. One example would be optimizing the bottom-up and top-down responses in vulnerable, coastal regions of nations with a high likelihood of tsunami occurrence, whether Talcahuano, Chile, Portland, Oregon, or Sendai, Japan. In an ideal world, citizens living in such areas would evacuate each time they felt or were warned of an earthquake and school children and adults alike would regularly practice walking, moving via wheelchairs, or running to higher ground. At the same time central government officials would put in physical infrastructure that effectively mitigated threats while creating escape zones that minimize dangers of inundation. Government agencies would also 
have pre-placed materials-including rescue, housing, food, and water-out of inundation zones but along resilient transportation routes into these areas.

But it is not immediately obvious that these two factors-bottom-up culture and top-down institutions-are in fact always compatible. This is because national frameworks can ignore local practice and indigenous knowledge may violate standardized laws. First, national, top-down responses may ignore indigenous practices. Hundreds of years ago, Japanese communities erected stones warning their neighbors against building homes at lower elevations near the ocean. For hundreds of years religious institutions in Tōhoku such as shrines and temples were all built above the inundation heights of the $3 / 11$ tsunami. Despite this institutional memory, regional and local zoning laws opened up low lying coastal property for residential development (Takase et al. 2012). Over time, these laws pushed locals to ignore embodied memory and move homes and businesses into vulnerable coastal zones.

Further, national institutions may press localities to take on standardized plans that go against local visions and goals and constrain local culture and innovation. Following the 1995 earthquake, the Kobe city government proposed innovative ways to raise money to create more independence in the recovery process but were not allowed to do so by the central government (Aldrich 1997). Despite a recognition that physical infrastructure may harm tourism and local fisheries, Japan's central and regional governments have pushed local communities to accept standardized seawall heights at 14.5 meters (Takezawa 2016).

Finally, indigenous knowledge and traditional practice may circumvent national laws or push beyond normative behavior (Mearns and Norton 2010). Local cultures of disaster may embrace events like flooding seen by decision makers as major threats to be managed. The Jamuna char dwellers in Bangladesh, for example, see flooding as a natural part of the life cycle that can bring benefits as well as threats, where Western educated engineers define them solely as risks (Schmuck-Widmann 1998). Similarly, the aboriginal cultures in Australia have long embraced active burning of local landscapes to reduce the likelihood of far more destructive fires (Spillman and Cottrell 2004). Following the 2004 Boxing Day tsunami, the Indian government insisted that all coastal dwellers move back $5 \mathrm{~km}$ from the sea in order to receive a new home, but local residents merely kept their old homes along with their new, more distant dwelling (Aldrich 2012).

In short, it may be that friction during disaster response is the norm, not the exception, and any attempts to move forward to reduce it must balance the importance of recognizing indigenous culture and practices whether in Japan, Sri Lanka, Nepal, or the Philippines (Shaw et al. 2009).

\section{Shortcomings and a Research Agenda}

This study has used a medium sized dataset of disasters around the world and as a result the dataset cannot be thought of as a representative sample. Because of data availability, most of these events occurred in the early twenty-first century. Further, while we used coders when categorizing our nine variables of interest, future teams should consider machine coding to provide stronger reliability in coding decisions. This is especially true for the outcome of interest, namely the level of coordination (or friction) in the response, which scholars have argued involves subjective judgment (Boin and Richardson 2015). Future studies should simultaneously build up a broader dataset of disasters-perhaps along the structure of EMDAT (CRED 2019) — while employing teams of simultaneous coders who can seek to accurately capture more ambiguous variables of interest.

\section{Conclusion and Policy Recommendations}

This article has sought to use qualitative comparative analysis, Tobit regression analysis, and mini-case studies to illuminate the factors that lead to friction-and not coordination-during disaster response. Across these methods the factors of the economic costs of the event, the level of development in the country, and the strength of logistical infrastructure having proven critical. In short, developed nations facing larger disasters with strong logistical infrastructure seem less likely to encounter friction during crisis. Unfortunately, less developed nations facing smaller scale disasters and using weaker infrastructure are more the norm, and more likely, based on these results, to have a lack of coordination.

The problem of balancing top-down and bottom-up approaches and ensuring smooth coordination will require creative political and administrative frameworks, perhaps ones not influenced strongly by political regime changes (Wood and Waterman 1991). While this article has focused partly on extreme weather-related events (including typhoons and floods), the pressing challenge of climate change will require simultaneous bottom-up adaptation and top-down legislative and institutional efforts that need to be coordinated well to avoid waste and achieve efficiency. One experimental approach to climate change adaptation has involved social learning, knowledge exchange, and social networks across levels of agency (Butler et al. 2015). Similarly large scale, cross-national private sector projects require horizontal and vertical integration of teams across firms and countries, and research has underscored the importance of identification and empowerment of leaders 
(Muller et al. 2018). Many industries struggle with the attempt to balance inflexible rule frameworks with local needs. In attempts to preserve critical aspects of heritage and culture, for example, conservators in museums and cultural institutions must navigate top-down initiatives from executives with bottom-up mandates from public stakeholders (Stoner 2009).

One cautionary tale about attempts to create coordination through top-down responses, as has often been the norm in developing and developed nations alike, revolves around the importance of bottom-up responses. The Fa'a Samoa, or Samoan culture, provided local residents with a bottom-up, accountable structure for responding to the 2009 tsunami without need for top-down institutions (Rumbach and Foley 2014). Societies that have unbalanced the interaction between top-down and bottom-up policies have paid the price. As societies face extreme weather events and climate change, they must recognize the need to integrate local residents and governments into response and recovery plans.

Acknowledgements Thank you to Haider Anwar and Zach Gavel for research assistance and coding and to scholars at the Mercatus Center at George Mason University, especially Stefanie Haeffele and Virgil Storr, for helping to spur and sponsor this research. And additional thank you to the multiple, anonymous referees and editors who helped improve the quality of this article through their feedback.

Open Access This article is distributed under the terms of the Creative Commons Attribution 4.0 International License (http://crea tivecommons.org/licenses/by/4.0/), which permits unrestricted use, distribution, and reproduction in any medium, provided you give appropriate credit to the original author(s) and the source, provide a link to the Creative Commons license, and indicate if changes were made.

\section{References}

Alcantra, P. 2014. Lessons learned from the Philippine government's response to Typhoon Haiyan. Journal of Business Continuity and Emergency Planning 7(4): 335-347.

Aldrich, D.P. 1997. Localities that can say no? Autonomy and dependence in Japanese local government. Asian Journal of Political Science 7(1): 60-76.

Aldrich, D.P. 2012. Building resilience: Social capital in postdisaster recovery. Chicago: University of Chicago Press.

Aldrich, D.P. 2019. Black wave: How networks and governance shaped Japan's 3/11 disasters. Chicago: University of Chicago Press.

Aldrich, D.P., and Y. Sawada. 2015. The physical and social determinants of mortality in the 3.11 tsunami. Social Science and Medicine 124: 66-75.

BCLC (Business Civic Leadership Center). 2010. What a successful disaster recovery looks like. https://www.uschamberfoundation. org/sites/default/files/publication/ccc/WhatDoesaSuccessfulRe coveryLookLike.pdf. Accessed 19 Aug 2019.

Below, R., and P. Wallemacq. 2018. Natural disasters 2017. Brussels: Centre for Research on the Epidemiology of Disasters (CRED).
Benson, C., and E. Clay. 2003. Economic and financial impacts of natural disasters: An assessment of their effects and options for mitigation. Washington, DC: World Bank.

Blakeman, B. 2017. Local governments must lead from the front during disasters. The Hill. 28 August 2017. https://thehill.com/ blogs/pundits-blog/economy-budget/348311-municipalitiesmust-lead-from-front-during-natural. Accessed 17 Jun 2019.

Boin, A., and F. Bynander. 2014. Explaining success and failure in crisis coordination. Geografiska Annaler, Series A, Physical Geography 97(1): 123-135.

Boin, A., and J. Richardson. 2015. Crisis management in Katrina's immediate aftermath: Lessons for a national response to a super disaster. Paper presented at the Katrina @10 Conference, 25 August 2015, Louisiana State University.

Boin, A., A. McConnell, and P. Hart. 2008. Governing after crisis: The politics of investigation, accountability and learning. New York: Cambridge University Press.

Butler, J.R.A., R.M. Wise, T.D. Skewes, E.L. Bohensky, N. Peterson, W. Suadnya, Y. Yanuartati, H.P. Handayani, et al. 2015. Integrating top-down and bottom-up adaptation planning to build adaptive capacity: A structured learning approach. Coastal Management 43(4): 346-364.

Clarke, L. 1999. Mission improbable: Using fantasy documents to tame disaster. Chicago: University of Chicago Press.

CRED (Centre for Research on the Epidemiology of Disasters). 2019. EM-DAT (Emergency Events Database). The international disaster database. Brussels, Belgium: Université catholique de Louvain, School of Public Health, Centre for Research on the Epidemiology of Disasters. https://www.emdat.be/. Accessed 20 Apr 2019.

De Bruin, K., R.B. Dellink, A. Ruijs, L. Bolwidt, A.V. Buuren, J. Graveland, R.S.D. Groot, P.J. Kuikman, et al. 2009.Adapting to climate change in The Netherlands: An inventory of climate adaptation options and ranking of alternatives. Climatic Change 95 (1-2): 23-45.

DHS (Department of Homeland Security). 2016. National disaster recovery framework, 2nd edn. https://www.fema.gov/medialibrary-data/1466014998123-4bec 8550930 f774269e0c5968b120ba2/National_Disaster_Recovery_Frame work2nd.pdf. Accessed 14 Aug 2019.

Dimmer, C. 2017. Japan after March 11th 2011: Between Swift reconstruction and sustainable restructuring. In Rethinking resilience, adaptation, and transformation in a time of change, ed. W. Yan, and W. Gallloway, 23-40. New York: Springer.

Dy, P., and T. Stephens. 2016. The typhoon Haiyan response: Strengthening coordination among Philippine government, civil society, and international actors. Cambridge, MA: Harvard Kennedy School Program on Crisis Leadership.

Edgington, D. 2010. Reconstructing Kobe: The geography of crisis and opportunity. Toronto: University of British Columbia Press.

Eyra, A., N. Fertel, J.M. Fisher, S.W. Gunn, D. Hampton, B. Lederman, Z. Posner, V.N. Preobrajensky, et al. 2001. Disaster coordination and management: Summary and action plans. Prehospital Disaster Medicine 16(1): 22-25.

Faraj, S., and Y. Xiao. 2006. Coordination in fast-response organizations. Management Science. 52(8): 1115-1169.

Fastenrath, S., and B. Braun. 2017. Sustainability transition pathways in the building sector: Energy efficient building in Freiburg. Applied Geography 90(1): 339-349.

Gall, M., S. Cutter, and K. Nguyen. 2014. Governance in disaster risk management (IRDR AIRDR publication No. 3). Beijing: Integrated Research on Disaster Risk.

Girdwood, J. 2013. Top down and bottom up approaches within implementation. Political Pipeline Blog 21 February.

GNDR (Global Network of Civil Society Organizations for Disaster Reduction). 2009. "Clouds but little rain..." Views from the 
Frontline; A local perspective of progress towards implementation of the Hyogo Framework for Action. Teddington, United Kingdom: GNCSODR. https://www.preventionweb.net/files/ 9822_9822VFLfullreport06091.pdf. Accessed 18 Jun 2019

Johnson, L., and R. Olshansky. 2017. After great disasters: An indepth analysis of how six countries managed community recovery. Cambridge, MA: Lincoln Institute for Land Policy.

Kendra, J.M., and T. Wachtendorf. 2016. American Dunkirk: The waterborne evacuation of Manhattan on 9/11. Philadelphia: Temple University Press.

Legewie, N. 2013. An introduction to applied data analysis with Qualitative Comparative Analysis (QCA). Forum on Qualitative Social Research 14(3): 1-45.

Manandhar, R., and D.A. McEntire. 2014. Disasters, development, and resilience: Exploring the need for comprehensive vulnerability management. In Disaster and development: Examining global issues and cases, ed. N. Kapucu, and K.T. Liou, 19-37. Cham, Switzerland: Springer.

Metaxa-Kakavouli, D., P. Maas, and D.P. Aldrich. 2018. How social ties influence hurricane evacuation behavior. Proceedings of the ACM on Human-Computer Interaction 2(CSCW): Article 122.

Mearns, R., and A. Norton. 2010. Social dimensions of climate change: Equity and vulnerability in a warming world. Washington, DC: The World Bank.

Muir-Wood, R. 2016. The cure for catastrophe. New York: Basic Books.

Muller, R., S. Sankaran, N. Drouin, A.L. Vaagaasar, M. Bekker, and K. Jain. 2018. A theory framework for balancing vertical and horizontal leadership in projects. International Journal of Project Management 36(1): 83-94.

Naderpajouh, N., D.J. Yu, D.P. Aldrich, I. Linkov, and J. Matinheikki. 2018. Engineering meets institutions: An interdisciplinary approach to the management of resilience. Environment Systems and Decisions 38(3): 306-317.

Oden, R., L.G. Militello, K. Ross, and C. Lopez. 2012. Four key challenges in disaster response. Proceedings of the Human Factors and Ergonomics Society 56th Annual Meeting, 22-26 October 2012, Boston, Massachusetts, USA.

Peregrine, P. 2018. Social resilience to climate-related disasters in ancient societies: A test of two hypotheses. Weather, Climate, and Society 10(1): 145-161.

Ragin, C. 2000. Fuzzy set social science. Chicago: University of Chicago Press.

Rumbach, A., and D. Foley. 2014. Indigenous institutions and their role in disaster risk reduction and resilience: Evidence from the 2009 tsunami in American Samoa. Ecology and Society 19(1): Article 19

Schmuck-Widmann, H. 1998. Floods in Bangladesh: Disaster or part of the lifeworld? Unpublished paper.

Shaw, R., and K. Godao. 2004. From disaster to sustainable civil society: The Kobe experience. Disasters 28(1): 16-40.

Shaw, R., Y. Takeuchi, N. Uy, and S. Sharma. 2009. Indigenous knowledge: Disaster risk reduction policy note. Bangkok,
Thailand: UN International Strategy for Disaster Reduction for Asia and the Pacific. www.preventionweb.net/english/profes sional/publications/v.php?id=8853. Accessed 19 Aug 2019.

Shi, P.J., C. Jaeger, and Q. Ye (eds.). 2013. Integrated risk governance: Science plan and case studies of large-scale disasters. Beijing: Beijing Normal University Press and Springer.

Siembieda, W.J. 2012. Transactions and friction as concepts to guide disaster recovery policy. International Journal of Disaster Risk Science 3(1): 38-44.

Spillman, M., and A. Cottrell. 2004. Indigenous communities, periurbanism and bushfire issues in Northern Australia. Briefing paper No 1. Centre for Disaster Studies, Tropical Environment Studies and Geography, James Cook University, Queensland, Australia. https://www.jcu.edu.au/_data/assets/pdf_file/0016/ 123631/jcutst_056280.pdf. Accessed 18 Jun 2019.

Stoner, J.H. 2009. Connecting the world's collections: Making the case for the conservation and preservation of our cultural heritage. Washington, DC: Institute of Museum and Library Services. $\quad$ https://scholar.google.com/citations?user= lB5FgRMAAAAJ\&hl=en\#d=gs_md_cita-d\&u=\%2Fcitations $\%$ 3Fview_op\%3Dview_citation\%26hl\%3Den\%26user\% 3DIB5FgRMAAAAJ\%26citation_for_view\% 3DlB5FgRMAAAAJ\%3AzYLM7Y9cAGgC\%26tzom\%3D240. Accessed 19 Aug 2019.

Suzuki, I., and Y. Kaneko. 2013. Japan's disaster governance: How was the 3.11 crisis managed? New York: Springer.

Takase, H., K. Yoshida, and W. Kumagai. 2012. Warnings from the shrines (Jinja wa keikoku suru). Tokyo: Kodansha.

Takezawa, S. 2016. The aftermath of the 2011 east Japan earthquake and tsunami: Living among the rubble. New York: Lexington Books.

Thomas, J., A.O. Mara-Eves, and G. Brunton. 2014. Using qualitative comparative analysis (QCA) in systematic reviews of complex interventions: A worked example. Systematic Reviews 3: Article 67.

Walch, C. 2018. Typhoon Haiyan: Pushing the limits of resilience? Critical Asian Studies 50(1): 122-135.

Watarai, A. 2012. Lessons learnt from the triple disaster in East Japan. Kanagawa: Institute for Global Environmental Strategies.

WHO (World Health Organization). 2013. Disaster coordination: The key to an effective response. Disasters issue 120. Geneva: WHO. https://www.paho.org/disasters\%20\%20/newsletter/index. php?option $=$ com_content $\&$ view $=$ article $\&$ id $=523 \% 3$ Adisaster coordination-the-key-to-an-effective-response $\&$ catid $=247 \% 3 \mathrm{Ais}$ sue-120-november-2013-editorial\&Itemid=319\&lang=en. Accessed 18 Jun 2019.

Wood, B.D., and R.W. Waterman. 1991. The dynamics of political control of the bureaucracy. American Political Science Review 85(3): 801-828.

Yamada, S. 2017. Hearts and minds: Typhoon Yolanda/Haiyan and the use of humanitarian assistance/disaster relief to further strategic ends. Social Medicine 11(2): 76-82. 